\title{
Entre a norma e a rebeldia: rastros de feminismos no sertão baiano
}

\author{
Between norm and disobedience: trails of feminisms in the bahian semi-arid \\ region
}

\author{
Vânia Nara Pereira Vasconcelos \\ https://orcid.org/0000-0002-8187-2614 \\ Universidade Estadual da Bahia
}

\begin{abstract}
Resumo: Pensando os sertões brasileiros como um espaço plural, diverso e potente, embora historicamente associado à fome, seca, a masculinidades dominantes e feminilidades submissas, neste artigo analiso as diversas formas de rebeldia feminina nesse território a partir de um estudo biográfico de uma mulher afro-indígena, não escolarizada, pertencente às camadas populares e moradora do sertão baiano. Sua narrativa me levou a refletir sobre as possibilidades de invenções de feminismos, considerando que estes foram construídos historicamente através do enfrentamento direto das mulheres à ordem androcêntrica, bem como por suas sutis formas de rebeldia. A partir de uma perspectiva decolonial, pretendo analisar as várias táticas utilizadas por esta mulher para subverter construções sociais de gênero, fazendo emergir "invenções de subjetividades" potentes e paradoxais.
\end{abstract}

Palavras-chave: Feminismos. Rebeldia. Sertões.

Abstract: Conceptualizing the Brazilian semi-arid regions as a diverse and potent plural space (though historically associated with hunger, drought, dominant masculinities and submissive femininities), in this article I use the biographic study of an unschooled, working class Afro-Indigenous woman living in the semi-arid region of Bahia to analyze various forms of female disobedience in this territory. Her narrative caused me to reflect on the possibilities for inventions of feminisms, considering that these were historically created by women's direct confrontation with the androcentric order as well as by their subtle forms of rebellion. Using a decolonial perspective, I intend to analyze the various tactics utilized by this woman to subvert social constructions of gender, giving rise to potent and paradoxical "inventions of subjectivities".

Keywords: Feminisms. Disobedience. Semi-arid regions.

\section{Introdução}

Os feminismos foram construídos historicamente através do enfrentamento direto das mulheres à ordem androcêntrica, bem como por suas sutis formas de rebeldia. O uso cada vez mais frequente do termo feminismos, no plural, em substituição a feminismo, no singular, revela a diversidade e multiplicidade das práticas dos movimentos e sujeitos/as envolvidos/as. A contribuição dos Estudos de Gênero ao questionar a existência e naturalização de um Sujeito Humano Universal (homem [macho], branco, cristão, heterossexual, cisgênero, eurocentrado) foi importante por denunciar o caráter universalista e androcêntrico tanto das produções acadêmicas, como das relações de poder presentes no cotidiano que definem quem é humano e tem o direito a existência plena (Fanon, 2008). Entretanto, o sujeito mulher que emerge nesses estudos, em um primeiro momento, tampouco dava conta das multiplicidades 
identitárias, não incluindo mulheres negras, indígenas, lésbicas, trans, bissexuais, nãocristãs, moradoras de pequenas vilas e espaços rurais, entre tantas outras.

Nesse sentido, o feminismo negro, e sua contribuição com o conceito de interseccionalidade (Crenshaw, 2004), o feminismo lésbico e o transfeminismo vão problematizar as diversas formas de exclusão e negação do direito de existência, tanto epistêmicas, quanto físicas, de determinados grupos sociais. Uma perspectiva decolonial nos traz a possibilidade de, além de questionar a eleição de um Sujeito Humano Universal, fazer implodir uma epistemologia que define, a partir da razão moderna, quais modos de viver, pensar, se relacionar são aceitos; e, estigmatiza, inferioriza, subalterniza, "outrifica" saberes, fazeres e práticas de sujeitos/as não escolarizados/as, não-binários, não brancos/os.

São muitas/os as/os sujeitas/os que sofrem historicamente de um epistemicídio (Santos e Meneses, 2010) praticado pelo processo de colonização dos corpos e das mentes. Mas neste artigo me interessa pensar, especialmente, nas mulheres que vivem à margem da cultura urbana e letrada, principalmente as de ascendência afro-indígena, não escolarizadas, pertencentes às camadas populares e moradoras do sertão baiano. A proposta deste artigo é analisar as diversas formas de rebeldia feminina nessa região buscando compreender como essas mulheres têm rompido fronteiras e construído novas formas de ser e estar no mundo.

Por se tratar de uma investigação em curso, o artigo sugere algumas reflexões acerca do tema, possíveis a partir da construção de uma biografia, realizada no doutorado, não apresentando resultados finais da pesquisa. Embora me refira em alguns momentos às mulheres sertanejas, desenvolverei o argumento a partir da narrativa de Dona Farailda, uma mulher nascida na cidade de Serrolândia" ${ }^{1}$ na Bahia.

Vivendo em um espaço marcado por fortes hierarquias de gênero, as mulheres sertanejas teceram suas trajetórias no diálogo entre a norma e a transgressão, subvertendo regras e fazendo escolhas que iam na contramão do que era aceitável para as mulheres de seu tempo e espaço (Vasconcelos, 2007). Essas narrativas me levaram a refletir sobre as possibilidades de invenções de feminismos, no sentido de investigar práticas que não foram consideradas pelo feminismo hegemônico.

Historicamente, as mulheres subverteram a ordem patriarcal em todo o mundo, seja oriental ou ocidental; no entanto, a forma como identificamos suas rebeldias ainda está marcado por referenciais pautados no colonialismo. Nesse sentido, como afirmam algumas feministas negras (Ribeiro, 2017), os marcadores das ondas do feminismo ocidental trazem como referenciais acontecimentos ligados à vida e às reivindicações das mulheres brancas e de classe média, eu acrescentaria, das mulheres urbanas.

As resistências femininas no cotidiano, tanto nos embates diretos, como nas formas sutis de enfrentamento às desigualdades de raça e gênero, são parte constitutiva da história das mulheres em condição de subalternidade. Nessa direção, a partir da trajetória de uma mulher do sertão baiano, pretendo analisar rastros de feminismos táticos. Estou chamando de feminismo tático ${ }^{2}$ a forma como mulheres foram inventando

\footnotetext{
${ }^{1}$ Serrolândia é um pequeno município do interior da Bahia, localizado no Piemonte da Chapada Diamantina, a $319,9 \mathrm{Km}$ de Salvador, na região Norte. De acordo com o IBGE, a população estimada do município era de 13.377 pessoas em 2019. Ver https://cidades.ibge.gov.br/brasil/ba/serrolandia/panorama.

2 O termo "feminismo tático" é utilizado pela historiadora Rachel Soihet (2006) para referir-se a Berta Lutz, uma importante feminista brasileira que lutou pelo voto das mulheres nas primeiras décadas do século XX. Assim, como fez a autora, utilizei na tese e pretendo dialogar nessa investigação com o conceito de "tática", de Michel de Certeau (2009) em seu livro A invenção do cotidiano: artes de fazer. De acordo com o autor, a tática seria a "arte do fraco", ela é parte de uma criatividade intelectual tão tenaz como sutil, pois não cria
} 
modos de enfrentamento aos dispositivos de vigilância de seus corpos e aos processos de inferiorização das suas existências; estou interessada principalmente nas maneiras criativas de rebeldia contra as diversas violências que sofreram historicamente, construindo linhas de fuga potentes e paradoxais.

Um dos princípios da produção acadêmica feminista é admitir, sem constrangimento, a construção de uma história posicionada. Acusadas de fazerem uma história interessada, as pioneiras dos estudos da História das Mulheres (Scott, 1992, p. 63-96) foram essenciais para questionar a neutralidade do fazer histórico, trazendo para a cena a impossibilidade de se produzir uma história desinteressada, sem posição política, límpida, sem cheiro, nem cor, enfim, sem disputas. Nesse sentido, apresento meu lugar de fala como mulher sertaneja, moradora de uma cidade do interior da Bahia até os 27 anos, historiadora feminista e ativista dos movimentos sociais, interessada, cada vez mais, nas formas criativas que as mulheres encontram para resistir às dominações de todos os tipos. Posso afirmar a partir da minha própria experiência, que a existência de rebeldia feminina em cidades interioranas e espaços rurais ainda surpreende pessoas que vivem nos grandes centros brasileiros e desconhecem essa realidade.

Este artigo surgiu de uma experiência de pesquisa. No doutorado, realizado na Universidade Federal Fluminense (UFF), estudei a trajetória de uma mulher moradora de uma pequena cidade no interior da Bahia, tendo como resultado a construção da biografia intitulada "É um romance minha vida": a trajetória de Dona Farailda - uma "casamenteira" no sertão baiano: gênero, memória, e construção de si (1929-2014)3. Esta senhora, nascida no ano de 1929, casou-se sete vezes ao longo da vida e realizou "casamentos de contrato" sem validade jurídica na década de 1980, afrontando a justiça local. A tese problematizou o fato de Dona Farailda ter um discurso normativo, reproduzindo em sua narrativa valores "tradicionais", como a defesa da família e do casamento monogâmico, e ao mesmo tempo ter práticas que parecem subverter normas estabelecidas para as mulheres daquela comunidade. Nesse sentido, utilizei os conceitos de "tática" de Michel de Certeau (2009), procurando compreendê-la como uma mulher que subverte sem o enfrentamento direto, agindo no campo oposto sem propor um contrapoder e, o de "paradoxo" de Joan Scott (2002), na perspectiva de positivar ações aparentemente contraditórias. Dialoguei ainda com o conceito de "subjetivação", de Foucault (1984), buscando compreender como Dona Farailda foi-se reinventando cotidianamente, rompendo com formas de sujeição presentes no contexto vivido, produzindo novos modos de "ser no mundo" e construindo possibilidades de "invenção de si”.

Alguns referenciais teóricos utilizados na construção da tese, como os citados acima, foram europeus e estadunidenses, embora eu também tenha dialogado com autoras e autores latino-americanas/os, principalmente brasileiras/os. Recentemente tive contato com uma bibliografia denominada por algumas/ns pesquisadoras/es como decolonial (Walsh, 2009; Espinosa Miñoso, 2011; Lugones, 2008, Marín, 2013) e me dei conta que, mesmo não tendo utilizado esses referenciais, o que revela como a academia é colonialista e colonizante, fiz alguns "ensaios decoloniais" na própria tessitura da tese. Este artigo pretende aprofundar esses ensaios a partir da trajetória da mulher estudada.

um contradiscurso direto, nem pretende atuar como um poder, mas está presente no cotidiano como rastro, astúcia.

${ }^{3}$ A tese foi publicada pela EDUFBA em 2017, com o título "É um romance minha vida": D. Farailda - uma "casamenteira" no sertão baiano. 


\section{Por que escutar narrativas de mulheres dos sertões?}

Pensando os sertões brasileiros como um espaço plural, diverso e potente, embora historicamente associado à fome, seca, a masculinidades dominantes e feminilidades submissas, este texto pretende afirmar a existência de outras representações sobre o feminino, a partir da trajetória de uma mulher que ousou transgredir os dispositivos de poder nesse espaço. De acordo com Vânia Vasconcelos \& Cláudia Vasconcelos:

Ao longo da História, as representações acerca do feminino no sertão, figuram em torno das ideias de submissão, da seriedade e da deserotização. Tanto as mulheres são vistas como subordinadas, não exercendo papel de sujeito das suas ações e práticas, como se configura uma idealização da sertaneja como "mulher séria". Essa "seriedade" estaria relacionada ao comportamento recatado ou sofrimento advindo da vida difícil que esta leva. Além disso, as imagens iconográficas que aparecem da mulher "tipicamente" sertaneja são compostas por uma certa ausência de sensualidade. (Vasconcelos, V. \& Vasconcelos, C., 2018, p. 149-166)

Ao aceitarmos essas representações históricas, nas quais a associação entre feminilidades sertanejas e submissão é frequente, cairemos em mais uma armadilha colonialista: a armadilha do estereótipo. O estereótipo nega a existência de sujeitos e sujeitas quando os enquadram em tipos idealizados; nesse caso, a idealização é recorrentemente negativa, sendo as mulheres sertanejas vistas como passivas, sem agenciamento, sem ação sobre suas vidas. Essa é uma imagem a ser desconstruída a partir de personagens reais que transgridem essa fronteira imaginária.

A/O sujeita/o subalterna/o pode ser definido, conforme Gayatri Spivak, como aquele que integra "as camadas mais baixas da sociedade, constituídas pelos modos específicos de exclusão dos mercados, da representação política e legal e da possibilidade de se tornarem membros plenos no estrato social dominante" (Spivak apud Almeida, 2010, p. 12). A autora sustenta que esta situação de subalternidade abrange diferentes grupos tendo se imposto ao longo dos séculos ao gênero feminino, já que a "mulher como subalterna, não pode falar e quando tenta fazê-lo não encontra os meios para se fazer ouvir" (Idem, ibdem, p. 15).

A história oral tem se apresentado como um importante recurso que possibilita a ascensão de vozes historicamente silenciadas, permitindo as/aos historiadoras/es fazerem emergir o que se chamou "uma história vista de baixo" (Sharpe, 1992, p. 3962) na qual sujeitas/os subalternizadas/os podem falar. Para construir esse tipo de narrativa pode-se usar outros tipos de fontes, além da oral, mas o trabalho com essa fonte torna possível colocar a subjetividade no centro, como defende Alessando Portelli (2010), ao invés de expurgá-la, como ocorreu com a emergência do positivismo no século XIX.

A rebeldia feminina nas pequenas cidades, nos espaços rurais ou interioranos ainda é invisibilizada na maioria dos estudos sobre mulheres brasileiras, o que reforça a visão de que esses lugares são espaços exclusivos de dominação hegemônica do masculino. Essa é mais uma versão da hierarquia centro/periferia, na qual se supõe que apenas nas grandes cidades se dão as rebeliões contra a ordem estabelecida.

Ao realizar pesquisas sobre a cidade de Serrolândia percebi mudanças e permanências nas representações de gênero, especialmente ao longo na segunda metade do século XX (Vasconcelos, 2007; 2017). Ao mesmo tempo em me deparei com hierarquias muito acentuadas, identifiquei formas criativas de resistências das mulheres 
a essas hierarquias. Nesse sentido, ao optar por estudar a vida de uma mulher que, mesmo imbricada discursivamente pelas teias normativas, questiona definições de gênero no espaço vivido, pretendi problematizar as possibilidades de resistências femininas pelo caminho da "rebeldia sutil". Considero as práticas, ou táticas, de Dona Farailda, como novas formas de enfrentamento das desigualdades de gênero, o que torna possível pensar que outras mulheres também tenham inventado novas perspectivas de subversão.

Um dos grandes "acertos" do colonialismo foi investir na destruição do conhecimento da/o sujeita/o colonizada/o. Esse investimento, que se deu por séculos na maior parte do mundo, nunca foi totalmente eficiente, embora tenha causado grandes estragos, especialmente para as mulheres e os não brancos. Quando a/o sujeita/o não se percebe capaz de pensar por si mesmo há um aniquilamento da sua existência. Ela/ele repete o outro, se identifica com ele, naturaliza a opressão sofrida, pois incorpora a inferioridade reificada cotidianamente (Freire, 2004). No caso das mulheres negras e indígenas isso se acentua consideravelmente, pois a dominação interseccional de raça e gênero torna ainda mais difícil a existência desse corpo a ser descartado, subjugado e silenciado. No entanto, a história dessas mulheres, visibilizadas pelos feminismos negro e indígena, tem mostrado a potencialidade da resistência. E é a partir dessa capacidade de (re) existir que me interessa estudar as mulheres sertanejas. De acordo com Maria Paula Meneses:

Uma das expressões mais claras da colonialidade das relações de poder acontece com a persistência da colonização epistêmica, da reprodução de estereótipos e formas de discriminação. [...] Este desaparecimento ou subalternização de outros saberes e interpretações do mundo significa, de facto, que estes saberes e experiências não são considerados formas compreensíveis ou relevantes de ser e estar no mundo; sendo estas epistemologias "outras" declaradas não existentes, ou descritas como reminiscências do passado, condenadas a um esquecimento inevitável. [...] Deste modo, a problemática da pós-colonialidade passa por uma revisão crítica de conceitos hegemonicamente definidos pela racionalidade moderna, como sejam história, cultura ou conhecimento, a partir de uma perspectiva e condição de subalternidade. [...] A presença de diferentes lógicas e diferentes formas de pensar, exige a possibilidade de diálogo e de comunicação entre culturas. A tradução intercultural, como proposta metodológica, revela o Sul global como um conjunto de epistemologias, extremamente dinâmicas. (Meneses, 2008, p. 6-7)

Penso a transgressão, o rompimento com a condição de subalternidade, citada pela autora, como potência para a construção de conhecimento, conhecimento este que se propõe a romper com a lógica das dualidades e da hierarquização dos saberes. Nesse sentido, estudar mulheres sertanejas significa produzir novos conhecimentos, mas também reconhecer sua produção de pensamento a partir de outras epistemologias. Seria possível pensar na existência de epistemologias feministas sertanejas?

Julieta Paredes, ao propor um rompimento com a dominação colonial, e suas lógicas e técnicas presentes nos Estados Nacionais atualmente, traz o conceito de despatriarcalização. No livro El desafío de la despatriarcalización, que escreve de forma coletiva com outras mulheres bolivianas, defende:

La despatriarcalización, en este marco, es el atrevimiento de las mujeres a soñar el mundo e no reducirnos solamente a visualizar las opresiones, violencias y dominaciones sobre nuestros cuerpos. [...] Es la contradicción de las mujeres mantuvimos permanentemente com un sistema que se fortalecía oprimiéndonos y 
que, con el hecho colonial de 1492, se agudiza y se fortalece mucho más al entroncarse dos patriarcados, el ancestral y el colonial. Son pensamientos, intuiciones y accciones que consisten en valorar nuestro pensamiento, nuestros cuerpos y nuestras acciones. Así fuimos, poco a poco, contruyendo la convicción de que somos nosostras mismas las que daremos solución a nuestros problemas, como parte de la búsqueda de solucionar los problemas de nuestros pueblos y comunidades. (Paredes, 2016)

Em sua proposta, baseada em uma experiência concreta de feminismo comunitário indígena praticado na Bolívia, de onde ela fala, são as mulheres que podem construir essas formas de rompimento com a dominação, não apenas para modificarem sua condição subalterna, mas também para proporem novas formas de vida para a comunidade, para os povos. Nesse sentido, sua experiência contribui, de forma significativa para as reflexões desenvolvidas neste artigo, na medida em que traz possibilidades de analisar as invenções de feminismos no sertão baiano, considerando outra perspectiva de narrativa, menos afetada pela hierarquia dos saberes.

\section{“Quem é essa mulher que fala?”: ensaios decoloniais na narrativa de uma mulher}

Atrevida, falante e com uma elevada autoestima, especialmente para uma mulher advinda de uma realidade na qual se calar, abaixar a cabeça, obedecer e principalmente, incorporar a inferioridade anunciada historicamente por ser mulher, afroindígena, pobre, não escolarizada e "da roça", é a regra, Dona Farailda emerge para mim como um presente. Presente como foi Menocchio para Ginzburg (2005), o moleiro italiano insistentemente atrevido, que preferiu perder a vida a abrir mão de suas convicções incômodas para a poderosa Igreja Católica do século XVI. Dona Farailda está viva! Vive uma vida retratada a partir das melhores recordações, não precisou morrer para afirmar suas verdades, ao contrário inventou formas de ser, dissimulando seu atrevimento, e muitas vezes construindo para mim (sua biógrafa) a personagem de mulher obediente, dócil, que aceita as regras impostas às mulheres de seu tempo/espaço. Mas da narrativa escapam as rebeldias, inúmeras... falar é uma delas. Fala, fala, fala, se coloca, subverte o lugar subalterno que a história lhe reservou, fala de si, fala da sua sexualidade, em uma sociedade na qual as mulheres não devem falar de sexo, muito menos de prazer e afeto. Não! O sexo é para procriar, atualmente ainda há correntes da Igreja Católica que defendem essa ideia. Mulheres devem servir a seus maridos, dando-lhes prazer e filhos. Umas o prazer, outras os filhos (de preferência homens!!!) para perpetuação da espécie, para perpetuação do poder masculino. Mulheres não devem falar de prazer, declará-lo como essencial às suas vidas é um ato rebelde. Mas Dona Farailda atreve-se e fala:

E aí eu estou aqui como diz a palavra: nunca aborreci o amor. Esse daqui (referindo-se ao sexto marido) dizia que pra se fazer sexo não tinha idade. [...] Eu num sabia disso, aprendi com ele. Ele que dizia. [...] Pra fazer amor muier não tem idade. Pra fazer sexo não tem idade. E é mesmo né? Não tem idade porque a pessoa quando ama, quando Deus deixou assim, por que assim é pra se fazer. [...] Eu já transei demais e nunca me enjoei. (Farailda Santos, 15.11.2011) Grifos meus

Então eu digo minha fia: muier sozinha o povo fala, o povo fala de quem não é só, quanto mais... Inveja de mim... era assim, o povo, as mulheres diziam: "ó danada, tu já foi já veio, você já fez isso?" Entendeu? Quanto a cidade dorme eu dava meu recado, mas com o capricho de eu sempre ter o meu do meu uso, né? Pra não 
deixar as mulher com raiva de mim. Mesmo assim eu também digo se eu morrer hoje não deixei ninguém com raiva de mim e por favor ninguém me faça raiva. (Farailda Santos, 09.02.2011) Grifo meu

Fala de uso do corpo, fala do corpo masculino como lugar de prazer para o feminino. Fala de afeto, vive o afeto na contramão dos que odeiam o afeto e condenam os amores fora da caixa normativa. Ela também tem suas contradições e não vê com bons olhos a sexualidade não normativa, mas esse não é o tema central da sua experiência, a vivência da sexualidade está no centro da sua narrativa, mas o responsável por esse atrevimento imperdoável para uma mulher nascida no ano de 1929 é Deus. Deus aparece em sua narrativa como o culpado ou, em melhores palavras, o responsável pelos atos rebeldes, o responsável pelos seus sete casamentos! 0 responsável pela prática de "casamentos de contratos" sem validade jurídica! Quando não foi Deus, foi o marido, que lhe ensinou sobre sexo na terceira idade, foi a vizinha que trouxe o novo marido e a apresentou, justo quando ela "não queria mais casar", pois "estava velha demais"... mas a vizinha trouxe... ela aceitou, aceitou e construiu uma bela narrativa de sedução do Sr. Severino, seu sétimo e atual marido. O casal se mostra apaixonado e o afeto é recorrente e explícito, seu comportamento está na contramão da suposta seriedade e deserotização das mulheres sertanejas.

Também fala de dores, das dificuldades da vida, da pobreza, dos tempos duros, mas fala sempre com beleza e tem uma capacidade de positivar a existência que deixaria Foucault (1984) em êxtase:

Tristeza? É alegria. Choro? É alegria. Eu choro de alegria. Quando eu medito assim, na minha vida assim, que Deus nunca me desamparou, né? Sou alegre com todo mundo. Sou alegre, nunca tive tristeza pra dizer que choro. Pra dizer que choro mesmo de tristeza. Não! Onde eu digo minha fia, eu choro de alegria! (Farailda Santos, 27.12.2013)

Em sua fala aparece a mulher que está absolutamente certa de que fez tudo o que podia (e que não podia!), tudo que quis fazer, não cita limites do cotidiano, nega minhas provocações à "condição de subalternidade das mulheres sertanejas": "tudo que eu fiz, como diz o outro, tudo que eu fiz de vida material, tudo que eu peguei pra fazer eu fiz. [...] Tudo o que eu sabia fazer e, as vez eu nem sabia fazer, e eu fiz, entendeu?" (Farailda Santos, 04.05.2012). Ela está mais interessada na potencialidade da vida do que nos processos de dominação, embora, em alguns momentos mostre revolta contra as hierarquias de gênero presentes no contexto vivido:

Porque tem homens que pensa que a mulher não tem direito. A mulher é fia do homem! A mulher mata, a mulher larga, a mulher pinta, a mulher borda! (fala com muita ênfase) Se o diabo entra nela e o veneno ajuda, se ela for uma mulher que não tenha Deus no coração, ela mata! Mata os home na cama! [...] Mas a mulher é fia do homem, ela não pode engolir umas certas coisas, o homem pensa que ele só que é o tal. Mas a mulher é fia do homem, o mesmo sangue que corre na veia da mulher, corre na veia do homem, tudo que o homem faz a mulher faz também! (Farailda Santos, 13.04.2006)

Mas a revolta explícita, declarada, não está no centro, esta é uma outra forma de criar-se, inventar-se, produzir-se... a produção de uma subjetividade potente, uma rebeldia que recorre à norma em seu discurso, mas realiza práticas a seu bel prazer, com direito à narrativa livre, supostamente sem cortes, sem seleção: 
O povo fala... Eu é porque eu... além da pessoa ter precisão do companheiro, a gente se sente sozinha, a gente se sente tão envergonhada de sair, sair e o povo do bairro ficar falando que tá saindo é porque tá caçando. Então eu prefiro me casar com aqueles viúvos, aquelas pessoas desocupadas [...] E eu gostava de casar... eu num queria amigar, né? Também nunca tomei nome de rapariga de ninguém. Todo mundo dizia: "era a mulher de fulano", né bonito? (Farailda Santos, 13.04.2006)

Mas o atrevimento vai bem mais além de ter-se casado sete vezes; sete vezes, como os poetas famosos das grandes metrópoles... poetas, homens, famosos, geralmente ricos e muitas vezes brancos... sete vezes não deveria ser para uma mulher! Especialmente se não é branca, nem rica, nem "estudada", e principalmente, se é uma mulher "da roça". O atrevimento maior foi praticar o ato ilegal de casar outros casais, num ritual de juntar amores "fora" da Igreja, "fora" do Fórum, sem validade jurídica, sem papel timbrado, afrontando o juiz, o padre, as beatas da Igreja, os pastores, as "pessoas de bem" da cidade. Enfim, constituiu-se como uma autoridade. Embora a história tenha mostrado que a constituição de autoridade e o poder de nomeação são feitos a partir de interesses econômicos (Bourdieu, 2005, p. 37) ${ }^{4}$ ela subverte mais uma vez, se constituindo como tal, já que o rito era parcialmente aceito pela comunidade (Thompson, 1998 , p. $305-352)^{5}$ e valorizado pelos casais que adentraram nessa aventura, estando juntos atualmente:

Eu já morava lá em Farailda, nós se conhecemos lá em Farailda, eu trabalhava lá, ele gostava de ir lá, [...] aí eu digo não vou casar não. Aí ela (Dona Farailda) ajeitou lá. [...] Aí nós casemos, já tem o que? Vinte e oito anos fez agora em novembro, no dia 20 de novembro fez vinte e oito anos, nós casamos, nunca separou não. (Abelarda Santos, 08.02.2011) Grifo meu

Se a história é uma invenção, se o casamento é uma invenção porque não inventar outras formas de casar-se, de divorciar-se, de encontrar-se. Com a prática dos "casamentos de contratos" Dona Farailda rompe com o conhecimento ocidental legitimado, afrontando a burocracia, outra invenção do colonialismo a partir de interesses econômicos, nos quais estão alinhadas (e aliadas) muitas instituições (também inventadas e legitimadas pelo Ocidente branco cristão heterocispatriarcal). Se o colonialismo inventou e impôs as formas como deveríamos viver, nesse sentido, inventar outras formas torna-se um atrevimento consideravelmente rebelde $\mathrm{e}$ necessário para nossa própria sobrevivência.

Uma forma de rebeldia histórica para as mulheres é cultivar a autoestima. Precisamos recuperá-la como uma das principais armas de rebeldia feminina. Virginia Woolf, com sua maravilhosa forma de provocar, já nos brindou com essa provocação. Ter autoestima para uma mulher, é por si só uma forma de transgressão. No ensaio "Um teto todo seu", escrito na década de 1920, a autora, ao refletir sobre as desigualdades entre homens e mulheres utilizando uma fina ironia, já refletia sobre o lugar de privilégio e as distorções que ele provoca na mentalidade dos privilegiados, nesse caso, os homens. Trazendo a reflexão para o momento atual, ela caberia também para refletir

\footnotetext{
${ }^{4}$ O sociólogo francês Pierre Bourdieu em formulações sobre o poder simbólico, conceito de grande contribuição para reflexão do tema do poder, discutiu o poder de nomeação, mostrando como os interesses econômicos podem influenciar na definição de quem pode dizer, de quem pode nomear, determinando o que é aceitável ou não em uma sociedade.

5 Discuto os "casamentos de contratos", realizados por Dona Farailda em Serrolândia, dialogando com o texto "A venda de esposas" de Edward Thompson, pensando-os como um ritual praticado pelas camadas populares que reafirma costumes "conservadores", ao mesmo tempo em que pode ser considerada uma prática rebelde, pela sua ilegalidade.
} 
sobre os privilégios de classe e raça:

Sem autoconfiança somos como bebês no berço. E de que modo podemos adquirir essa qualidade imponderável que também é tão inestimável o mais rápido possível? Pensando que as outras pessoas são inferiores. Sentindo que temos uma superioridade inata [...] Por isso a enorme importância para o patriarcado de ter de conquistar, de ter de governar, de achar que um grande número de pessoas, metade da raça humana, na verdade, é por natureza inferior. Deve ser realmente uma das principais fontes do seu poder. (Woolf, 1985)

Se uma forma de garantir e exercer o poder é convencer-se da própria superioridade, segundo a autora, para isso seria necessário convencer a/o outra/o de que é inferior. Se pensarmos na história do Brasil podemos afirmar que mulheres, negras/os, indígenas, sertanejas/os e nordestinas/os, entre outros, sofreram um processo de tentativa de convencimento, a partir do racismo científico e outras teorias, muitas das quais importadas da Europa, da sua inferioridade. É nesse sentido que busco provocar a pensar que uma mulher com uma autoestima elevada é por si só uma ameaça ao sistema de classificação hierárquico de gênero. $E$ eis o que encontro na construção de si de Dona Farailda: a autoestima no centro da narrativa. Ela não apenas se constrói como uma mulher feliz, mas também elabora uma fábula de aceitação social improvável naquela sociedade, no entanto, essa foi a forma que encontrou para sobreviver às discriminações que também faziam parte do seu cotidiano.

\section{Considerações finais ou algumas perguntas...}

Um dos desafios de escrever sobre mulheres sertanejas, ou sobre a existência de práticas feministas nos sertões brasileiros, está em encontrar uma linha de equilíbrio entre enxergá-las para além da condição de meras "vítimas do patriarcado", considerando que há um imaginário construído historicamente que afirma que as hierarquias de gênero nos sertões são mais acentuadas que em outros territórios brasileiros, e/ou colocá-las em um pedestal como mulheres mais revolucionárias e rebeldes que quaisquer outras, pela sua suposta propensão à fortaleza, a um poder da ancestralidade rural. Como não cair nesse dualismo simplista que não dá conta das experiências e complexidade da vida dessas mulheres?

Minha proposta nesse artigo é abrir espaço para algumas reflexões sobre as invenções de feminismos nos sertões. Esse texto é muito mais uma provocação que um escrito para responder a questões acerca desse universo pouco estudado, pouco conhecido, e por muito tempo invisibilizado e estereotipado. A imagem da "mulher macho, sim senhor!", forte, brava e ao mesmo tempo submissa e deserotizada, só pode ser questionada a partir de personagens reais. Essa foi a minha tentativa aqui. Embora tenha trazido apenas uma personagem (a minha pretensão é ampliar a pesquisa estudando outras trajetórias), considero ser este um ponta pé inicial para desenvolver algumas questões que exponho a seguir:

Parto das contribuições do feminismo negro e indígena, que problematiza não só uma ausência, mas um silenciamento de parte das produções do feminismo brasileiro acerca da existência das mulheres negras e indígenas e do racismo estrutural que marca suas vidas (Carneiro, 2003), para pensar outra exclusão: das mulheres moradoras de pequenas vilas e espaços rurais, das mulheres sertanejas. Ainda são poucos os trabalhos que discorrem sobre a vida dessas mulheres. Essa provocação não é um julgamento. Não tenho a intenção de desconsiderar a importância dessa produção, 
pois é preciso considerar que as questões identitárias não estavam em pauta quando se iniciou o debate de gênero nos anos 1980, pelo menos não da forma como estão colocadas atualmente, especialmente após as contribuições de Butler (2003) acerca do questionamento dos binarismos, entre outras.

Seria possível pensar na existência de uma epistemologia feminista sertaneja, considerando que, provavelmente, as práticas dessas mulheres não cabem nas formulações elaboradas por um feminismo urbano, branco e de classe média? Ainda é cedo para responder à questão, mas o que posso sugerir, a partir de estudos desenvolvidos por mim e por outras historiadoras, é a existência de práticas feministas sertanejas. Essas mulheres utilizaram de táticas de negociação, incorporando muitas vezes um discurso normativo, mas ao mesmo tempo atuando de forma rebelde. Se apropriaram de construções sobre elas para inverter a lógica da dominação, exercendo o que Rago (2013) chamou de "invenções de subjetividades". Não estou afirmando que outras mulheres, que vivem em outros territórios brasileiros, não tenham atuado de forma semelhante, no entanto, pretendo investigar certas especificidades nas formas de reagir aos processos de subalternização, problematizando disputas de poder nesse campo de investigação.

Finalizo com duas contribuições de pensadoras feministas, uma brasileira, outra estadunidense, que mapearam o campo dos feminismos na atualidade. Bell Hooks me trouxe a dimensão das experiências feministas não nomeadas pela autoridade acadêmica, desenvolvidas em seu livro, recentemente traduzido no Brasil, Feminismo é para todo mundo (2019). Heloisa Buarque de Holanda, em Explosão feminista (2018) me fez pensar sobre quantas possibilidades de práticas feministas existem pelo Brasil afora, que nos escapam por estarmos centradas em nossas teorias acadêmicas, muitas vezes distantes dos "palcos insubmissos", que podem estar tanto no movimento de mulheres, quanto nas casas, nos bares, nas zonas, nas ruas...

\section{Referências}

BUTLER, Judith. Problemas de gênero: feminismo e subversão da identidade. Rio de Janeiro: Civilização Brasileira, 2003.

CARNEIRO, Sueli. Enegrecer o feminismo: a situação da mulher negra na América Latina a partir de uma perspectiva de gênero. In: Ashoka Empreendimentos Sociais; Takano Cidadania (Org.). Racismos contemporâneos. Rio de Janeiro: Takano Editora, 2003, vol. 49, p. 49-58.

CERTEAU, Michel de. A invenção do cotidiano: artes de fazer. Rio de Janeiro: Vozes, 2009.

CRENSHAW, Kimberle W. A interseccionalidade na discriminação de raça e gênero. In: V. AA. Cruzamento: raça e gênero. Brasília: Unifem, 2004.

ESPINOSA MIÑOSO, Y.; CASTELLI, R.; ALVAREZ, V. Colonialidad y dependencia en los estudios de género y sexualidad en América Latina: un informe de avance. II Jornadas del Centro Interdisciplinario de Investigaciones en Género, 28, 29 y 30 de septiembre de 2011, La Plata, Argentina. En Memoria Académica. Disponível em http://www.memoria.fahce.unlp.edu.ar/trab_eventos/ev.4889/ev.4889.pdf. Acesso em 16 jul. 2019.

FANON, Frantz. Pele negra, máscaras brancas. Salvador: EDUFBA, 2008. 
FOUCAULT, Michel. História da sexualidade: o uso dos prazeres, Rio de Janeiro: Graal, 1984.

FREIRE, Paulo. Pedagogia do oprimido. Rio de Janeiro: Paz e Terra, 2004.

GINZBURG, Carlo. O queijo e os vermes: o cotidiano e as ideias de um moleiro perseguido pela Inquisição. São Paulo: Companhia das Letras, 2005.

HOLANDA, Heloisa Buarque. Explosão feminista: arte, cultura, política e universidade. São Paulo: Companhia das Letras, 2018.

hooks, bell. Feminismo é para todo mundo: políticas arrebatadoras. Rio de Janeiro: Rosa dos Tempos, 2019.

LUGONES, María. Colonialidad y Género. Tabula Rasa, Bogotá, n. 9, jul./dic. 2008, p. 73-101.

MARÍN, Pilar. Cuevas. Memoria colectiva: hacia un proyecto decolonial. In: WALSH, Catherine (org.). Pedagogías decoloniales: prácticas insurgentes de resistir, (re)existir y (re)vivir. Quito: Ediciones Abya-Yala, 2013, p. 69-103.

MENESES, Maria Paula. Introdução: Epistemologias do Sul. Revista Crítica de Ciências Sociais, n. 80, mar. 2008, p 5-10.

PAREDES, Julieta. El desafío de la despatriarcalización: entramado para la liberación de los pueblos. La Paz: Moreno Artes Gráficas, 2016.

PORTELLI, Alessandro. Ensaios de História oral. São Paulo: Letra e Voz, 2010.

RAGO, Margareth. A aventura de contar-se: feminismos, escrita de si e invenções da subjetividade. Campinas: Editora da Unicamp, 2013.

RAGO, Margareth. Práticas feministas em novos modos de subjetivação. Revista Maracanan, Rio de Janeiro, n. 4, abri./dez., 2008, p. 13-36.

RIBEIRO, Djamila. Feminismo negro: para além de um discurso identitário. Revista Cult, São Paulo, jun., 2017. Disponível em: < https://revistacult.uol.com.br/home/feminismonegro-paraalem-de-um-discurso-identitario/>. Acesso em 16 jul. 2019.

SANTOS, Boaventura de Sousa; MENESES, Maria Paula. (Orgs.) Epistemologias do Sul. São Paulo: Editora Cortez, 2010.

SCOTT, Joan. História das Mulheres. In: BURKE, Peter (Org). A Escrita da História: novas perspectivas. São Paulo: UNESP, 1992, p. 63-96.

SCOTT, Joan. A cidadã paradoxal. As feministas francesas e os direitos do homem. Florianópolis: Editora das Mulheres, 2002.

SOIHET, Rachel. O feminismo tático de Bertha Lutz. Florianópolis: Editora das Mulheres, 2006.

SHARPE, Jim. A história vista de baixo. In: BURKE, Peter (org.). A Escrita da História: novas perspectivas. São Paulo: Fundação Editora da UNESP, 1992, p. 39-62.

SPIVAK, Gayatri Chakravorty. Pode o subalterno falar? Belo Horizonte: Editora da UFMG, 2010. 
THOMPSON, Edward. A venda das esposas. In: THOMPSON, Edward. Costumes em comum. São Paulo: Companhia das Letras, 1998, p. 305-352.

VASCONCELOS, Vânia; VASCONCELOS Cláudia. "Mulher séria" e "cabra macho": por outras representações de gênero no sertão. In: RIOS, Pedro Paulo; MENDES, Alane Martins. Educação, gênero e diversidade sexual: fabricação das diferenças no espaço escolar. Curitiba: CRV, 2018, p. 149-166.

VASCONCELOS, Vânia. É um romance minha vida: D. Farailda uma "casamenteira" no sertão baiano. Salvador: EDUFBA, 2017.

VASCONCELOS, Vânia. Evas e Marias em Serrolândia: práticas e representações acerca das mulheres em uma cidade do interior (1960-1990). Salvador: EGBA, Fundação Pedro Calmon, 2007.

WALSH, Catherine. Interculturalidad, Estado, Sociedad: luchas (de)coloniales de nuestra época. Quito: Ediciones Abya-Yala, 2009.

WOOLF, Virginia. Um teto todo seu. Rio de Janeiro: Nova Fronteira, 1985.

\section{Entrevistas orais}

Abelarda Santos. Entrevista concedida a Vânia Nara Pereira Vasconcelos no dia 08.02.2011

Farailda Santos. Entrevista concedida a Tânia Mara Pereira Vasconcelos no dia 13.04.2006

Farailda Santos. Entrevista concedida a Vânia Nara Pereira Vasconcelos no dia 09.02.2011

Farailda Santos. Entrevista concedida a Vânia Nara Pereira Vasconcelos no dia 15.11.2011

Farailda Santos. Entrevista concedida a Vânia Nara Pereira Vasconcelos no dia 04.05.2012

Farailda Santos. Entrevista concedida a Vânia Nara Pereira Vasconcelos no dia 27.12.2013

\section{Notas de autoria}

Vânia Nara Pereira Vasconcelos é professora Adjunta da UNEB na graduação e no Programa de pós-graduação em História Regional e Local. Doutora em História pela UFF, com período sanduíche na Universitat Rovira i Virgili (Espanha). Desenvolve pesquisas sobre gênero, sexualidades, feminismos, mulheres e biografia, tendo publicado recentemente o livro "É um romance minha vida": D. Farailda - uma "casamenteira" no sertão baiano. Atualmente realiza um pós-doutorado no Centro de Estudos Sociais, na Universidade de Coimbra. E-mail: vaniauneb5@gmail.com.

\section{Como citar esse artigo de acordo com as normas da revista}

VASCONCELOS, Vânia Nara Pereira. Entre a norma e a rebeldia: rastros de feminismos no sertão baiano. Sæculum - Revista de História, v. 24, nº 41, p. 204-216, 2019. 
Contribuição de autoria

Não se aplica.

Consentimento de uso de imagem

Não se aplica.

Aprovação de comitê de ética em pesquisa

Não se aplica.

\section{Licença de uso}

Este artigo está licenciado sob a Licença Creative Commons CC-BY. Com essa licença você pode compartilhar, adaptar, criar para qualquer fim, desde que atribua a autoria da obra.

Histórico

Artigo recebido em 25/08/2019.

Artigo aprovado em 10/10/2019. 